\title{
Gut contents in molting lepidopteran larvae: a source of error in nutritional studies
}

\author{
R. V. Barbehenn ${ }^{1} \&$ A. Keddie ${ }^{2}$ \\ University of California, Department of Entomology, Berkeley, CA 94720, USA; Current addresses: \\ ${ }^{1}$ Department of Biology, University of Michigan, Ann Arbor, MI 48109-1048. USA; ${ }^{2}$ Department of \\ Entomology, 2-27 Earth Sciences Building, University of Alberta, Edmonton, Alberta, Canada T6G 2E3
}

Accepted: July 9,1991

Key words: Molting, Lepidoptera, nutritional indices

\section{Introduction}

It is generally assumed that larval insects allow the gut to clear of all food prior to each molt (Waldbauer, 1968; Kogan, 1986; Ayres \& MacLean, 1987). This premise has been important in the standardization of insect starting weights in growth experiments; the food in feeding larvae may account for up to $50 \%$ of the dry weight of phytophagous in sects (Wightman, 1981; Kogan, 1986). The only published reference that we found of a lepidopteran species which does not clear its gut during molting was Spodoptera eridania (Cram.) (Soo Hoo, 1962 in Waldbauer, 1968). The finding that Paratrytone melane Edwards larvae also consistently contain a substantial amount of food in the midgut during and following a molt (Barbehenn, 1989) prompted us to make a survey of molting lepidopteran larvae in order to generalize about the prevalence of this putatively rare phenomenon. We also present a method for estimating the correct initial dry weights (DW) of larvae of species which retain food in their guts during a molt.

\section{Materials and methods}

Eggs or young larvae of each species were collected at field sites near Berkeley, California or were acquired from laboratory colonies. Most species were reared on one of their host plants (Table 1) in cages kept at approximately $25^{\circ} \mathrm{C} \pm 5^{\circ}$ in natural light (approximately 15L.9D). Species reared on artificial diets were kept under similar environmental conditions. Larvae to be dissected were examined daily and frozen when they were observed to be in the 'head-capsule slippage' stage of a molt to a late or final instar. The head-capsule slippage stage is characterized by the presence of the head capsule of the previous instar partially covering the newlyformed, unhardened head capsule of the next instar. This provided a means of assuring that larvae had not recently been feeding. We assumed that larvae at this stage of molting did not have time to further evacuate their midguts before ecdysis was completed. Exceptions to this protocol for collecting larvae were all $P$. melane larvae and several Agraulis vanillae (L.) larvae, which were dissected after ecdysis. Larvae of 18 species were dissected and their gut contents examined under a dissecting microscope.

We used $P$. melane to study the effects of gut contents in newly-molted, final-instar larvae on growth and consumption rates and nutritional indices. P. melane were reared on either Cynodon dactylon (L.) Pers. or Lolium multiflorum Lam. (Poaceae), which were grown from seed in six 
Table I. Lepidopteran larvae surveyed for the presence of food in their guts during molting to final or penultimate instars

\begin{tabular}{|c|c|c|c|}
\hline Species & Food & $\begin{array}{l}\text { Gut } \\
\text { contents }\end{array}$ & $\begin{array}{l}\text { Number } \\
\text { observed }\end{array}$ \\
\hline \multicolumn{4}{|l|}{ Tortricidae } \\
\hline Cydia pomonella (L.) & artificial diet & - & 8 \\
\hline \multicolumn{4}{|l|}{ Hesperiidae } \\
\hline Paratrytone melane Edwards & Poaceae (several spp.) & + & 113 \\
\hline \multicolumn{4}{|l|}{ Pyralidae } \\
\hline \multicolumn{4}{|l|}{ Nymphalidae } \\
\hline Junonia coenia Hubner & Plantago lanceolata $\mathbf{L}$. & + & 5 \\
\hline $\begin{array}{l}\text { Euphydruas chalcedona Doubleday } \\
\text { and Hew. }\end{array}$ & Mimulus aurantiacus Curt & + & 4 \\
\hline Agratilis vanillae (L.) & Passiftora sp. & + & 6 \\
\hline \multicolumn{4}{|l|}{ Zygaenidae } \\
\hline Harissina americana (Guerin) & Vitis sp. & - & 5 \\
\hline \multicolumn{4}{|l|}{ Bombycidae } \\
\hline Bambyx mori (L.) & Morus alba $\mathrm{L}$. & + & 8 \\
\hline \multicolumn{4}{|l|}{ Lasiocampidae } \\
\hline Malacosoma californicum (Packard) & Quercus agrifolia Nęe & + & 5 \\
\hline $\begin{array}{l}\text { Saturniidae } \\
\text { Hyalophora cecropia (L.) }\end{array}$ & artificial diet & - & $?^{2}$ \\
\hline $\begin{array}{l}\text { Sphingidae } \\
\text { Manduce sexta (L.) }\end{array}$ & Nicotiana tabacum L. & - & 5 \\
\hline \multicolumn{4}{|l|}{ Dioptidae } \\
\hline Phyganidia californica & Quercus agrifolia Nee & - & 5 \\
\hline \multicolumn{4}{|l|}{ Lymantriidae } \\
\hline Orgyia vetusta (Boisduval) & Quercus agrifolia Nee & - & 1 \\
\hline Orgpia leucostigma (I. E. Smith) & artificial diet & - & 6 \\
\hline \multicolumn{4}{|l|}{ Nactuidae } \\
\hline Heliothis zea (Boddie) & Triticum aestivum L. & $5+15-$ & 10 \\
\hline Pseudaletia unipuncta (Haworth) & Triticum aestivum L. & $2+\sqrt{3}-$ & 5 \\
\hline \multirow[t]{2}{*}{ Spodoptera eridania (Cram.) } & $?$ & + & $?^{3}$ \\
\hline & artificial diet & + & 5 \\
\hline Spodoptera frugiperda (J. E. Smith) & Triticum aestivum $\mathrm{L}$. & + & 7 \\
\hline \multirow[t]{2}{*}{ Trichoplusia ni (Hubner) } & Mentha sp. & - & 5 \\
\hline & artificial diet & - & 20 \\
\hline
\end{tabular}

$\mathrm{l}+=$ food present, - = food absent.

I Schroeder, unpubl.

3 Soo Hoo, 1962 in Waldbater, 1968.

inch pots in a greenhouse. Larvae were weighed following edysis on a Sartorius electronic balance to the nearest $0.1 \mathrm{mg}$. They were kept individually in $275 \mathrm{ml}$ plastic cups in a controlled environment chamber with a light:dark cycle of
$12 \mathrm{~h}: 12 \mathrm{~h}$ and corresponding temperatures of $30^{\circ} \mathrm{C}: 20^{\circ} \mathrm{C}$. Freshly gut grasses were weighed and presented to larvae in vials of water on a daily basis. All frass and the remains of uneaten grasses were dried at $70^{\circ} \mathrm{C}$ and weighed. Relative growth 
rate ( $R G R$ ), relative consumption rate ( $R C R$ ), approximate digestibility (AD), efficiency of conversion of ingested food to body weight (ECI), and efficiency of conversion of digested food to body weight (ECD) were calculated on a dry weight basis (Waldbauer, 1968). RGR and RCR were calculated using exponential mean weights (mg/mg mean DW/day) (Montgomery, 1983). Uncorrected and corrected initial DW, RGR, $\mathrm{RCR}$ and nutritional indices were compared using the Mann-Whitney U-test.

Two additional groups of newly-molted $P$. melane larvae which had fed on C. dactylon $(\mathrm{n}=10)$ or L. multiflorum $(\mathrm{n}=14)$ were dissected in order to quantify the relationship between body weight and the weight of their gut contents. Each larva was weighed and then chilled for approximately five minutes in a freezer to slow its movements. Each intact peritrophic membrane, containing all midgut contents, was removed and placed on a weighed piece of aluminum foil. Peritrophic membranes were then dissected from the gut contents and placed, along with the dissected body, on a weighed piece of aluminum foil. All samples were dried at $70^{\circ} \mathrm{C}$ and weighed. Prior to statistical analysis, body and gut content weights were tested for homoscedasticity with the Bartlett test and for normality by plotting the residuals (Wilkinson, 1987).

\section{Results and discussion}

All individuals examined from eight species contained food in their midguts during their molt to the final or penultimate instar (Table 1). At least. some individuals from three additional species also contained food in their midguts during this time. Eight of the 19 species of Lepidoptera surveyed completely cleared their guts prior to molting. Some individuals in four species also contained undigested food in their hindguts during the molt: Euphydryas chalcedona Doubleday and Hew. (1 of 4), Bombyx mori (L.) ( 1 of 8 ), Malacosoma californicum (Packard) (1 of 5), and Heliothis zea (Boddie) (4 of 10). Only in $H$. zea were frass pellets formed; hindguts of the other species contained loose leaf pieces. No food particles were found in the foreguts of any species.

Correcting for gut content weights using a regression equation avoids the problems of stressing larvae during a period of starvation and is more accurate than direct collection of the gut contents as frass due to incomplete egestion (Waldbaner, 1968). Regressions of the DW of dissected newly-molted $P$. melane against their total fresh weights (FW) were (corrected DW $)=\mathrm{FW} * 0.079+1.88\left(\mathrm{r}^{2}=0.927 ; \quad P<0.001\right)$ for larvae fed $C$. dactylon and (corrected $\mathrm{DW})=\mathrm{FW} * 0.069+2.09\left(\mathrm{r}^{2}=0.883 ; \quad P<0.001\right)$ for larvae fed $L$. multiflorum. Regressions of the corrected DW of newly-molted fourth- and fifthinstar $P$. melane larvae against their total FW were also highly significant in other experiments (Barbehenn, unpub.) and were used for converting fresh weights to corrected dry weights. In addition, gut contents (DW) of newly-molted $P$. melane fed $C$. dactylon or $L$. multiflorum were highly correlated with total body DW (Pearson's correlation; $r^{2}=0.851, P<0.001$ and $r^{2}=0.663$, $P=0.004$, respectively). An analysis of covariance, comparing the regressions of gut contents (DW) against total body DW for larvae fed C. dactylon and $L$. multiflorum, showed no differences in their intercepts ( $\mathrm{P}=0.88$ ). Therefore, there was no effect of host plant on the relationship between gut contents and body weight for larvae fed either grass species. This method for correcting initial DW of larvae may be of limited value in species which vary greatly in the presence or absence of food in their guts during molting, e.g., $H . z e a$ and Uresiphita reversalis (Guenee) (Table 1).

Table 2 presents a comparison of initial DW, RGR, RCR, and nutritional indices for $P$. melane uncorrected and corrected for the gut contents in newly-molted larvae. The weight of the gut contents caused an 18-19\% overestimate of initial DW in larvae reared on C.dactylon and L. multiflonum. This overestimate, in turn, led to underestimates of RGR, RCR, ECI, and ECD values. RGR values of larvae reared on $C$. dactylon were significantly underestimated $(P<0.05)$. RGR values of larvae reared on $L$. multiflorum 
Table 2. Growth and consumption rates and nutritional indices of fifth-instar Paratrytone melane larvae reared on two grasses. Data (mean and standard error) are presentged with and without correction for the weight of food remaining in the gut in newly-molted larvae

Larvae fed Cynodon dactplon $(\mathrm{n}=15)$

\begin{tabular}{lccrrr}
\hline & Uncorrected & Corrected & \% Change & $P^{2}$ \\
\hline DW ${ }^{\prime}$ & $12.00(0.43)$ & $9.79(0.26)$ & $-18.09(0.75)$ & $<0.001$ \\
RGR & $0.085(0.004)$ & $0.096(0.004)$ & $+13.07(0.91)$ & 0.046 \\
RCR & $0.92(0.051)$ & $0.99(0.055)$ & $+7.67(0.41)$ & 0.272 \\
AD & $40.42(2.32)$ & $39.95(2.33)$ & $-1.24(0.16)$ & 0.633 \\
ECI & $9.47(0.44)$ & $9.94(0.45)$ & $+4.99(0.45)$ & 0.220 \\
ECD & $25.29(2.78)$ & $26.56(2.90)$ & $+5.07(0.43)$ & 0.520 \\
\hline
\end{tabular}

Larvae fed Lolium multiflonum $(\mathbf{n}=14)$

\begin{tabular}{|c|c|c|c|c|}
\hline & Uncortected & Corrected & $\%$ Change & $P$ \\
\hline DW & $12.19(0.39)$ & $9.87(0.23)$ & $-18.72(0.76)$ & $<0.001$ \\
\hline RGR & $0.11(0.005)$ & $0.12(0.005)$ & $+11.51(0.60)$ & 0.089 \\
\hline RCR & $0.83(0.032)$ & $0.90(0.033)$ & $+7.54(0.36)$ & 0.183 \\
\hline $\mathrm{AD}$ & $48.53(1.82)$ & $48.05(1.83)$ & $-1.04(0.091)$ & 0.696 \\
\hline ECI & $13.40(0.71)$ & $13.89(0.73)$ & $+3.68(0.22)$ & 0.550 \\
\hline ECD & $28.59(2.52)$ & $29.63(2.58)$ & $+3.68(0.22)$ & 0.395 \\
\hline
\end{tabular}

${ }^{1} \mathrm{DW}$ = initial dry weight of larvae, $\mathrm{RGR}=$ relative growth rate, $\mathrm{RCR}=$ relative consumption rate, $\mathrm{AD}=$ approximate digestibility, $\mathrm{ECI}=$ efficiency of conversion of ingested food, and $\mathrm{ECD}=$ efficiency of conversion of digested food.

2 Probabilities of differences between uncorrected and corrected values using the Mann-Whitney U-test.

were also underestimated, but this difference was not significant $(P>0.05)$. RCR, ECI and ECD were affected less than RGR values, varying on average from underestimates of $3.7 \%$ to $7.7 \%$. Only small errors in AD values resulted when the weight of frass produced from the gut contents from the previous instar was not subtracted from the total amount of frass produced during the experimental instar.

Several studies have reported that, despite the genetic similarity of insects and homogeneous environmental conditions used in experiments, variation between insects was a major source of variation in nutritional indices (Parra and Kogan, 1981; Schroeder, 1984). This individual variation may be caused in part by variation in the weight of gut contents of newly-molted larvae which are assumed to have empty guts. Significant reductions in the variation in initial DW of newlymolted P. melane larvae fed C. dactyion and $L$. multiflorum were found after they were corrected for gut contents (Table 2; F-test; $P<0.05$ ).
Use of the final instar in experiments eliminates the need to correct for gut contents at the end of the experiment since the gut is completely cleared prior to pupation; only a meconium containing pupal metabolic waste products was produced following pupation in P. melane, Pseudaletia unipuncta (Haworth), Manduca sexta (L.), and $U$. reversalis (Barbehenn, pers. obs.), and this is believed to be the case in Lepidoptera in general (Chapman, 1982). Alternatively, use of the penultimate or earlier instars in experiments may reduce the magnitude of the error in measurements of larval growth during an instar since gut contents, when present, would be present in larvae at the beginning and end of an experiment. Further work is needed on the magnitude of errors in this case.

Because there is wide variation between larval Lepidoptera in the presence of food in the gut during molting, larvae of each species should be examined for gut contents before their use in experiments in which this may be a concern, such 
as in nutritional studies, studies of molting time (Ayres \& MacLean, 1987; Stamp, 1990), and bioassays for viral susceptibility (Briese, 1986). Further work is needed on the potential benefits of the maintenance of food in the midgut during molting, such as greater digestive efficiency or reduced susceptibility to diseases.

\section{Acknowledgements}

We thank Elizabeth A. Bernays, Michael M. Martin, and Lauren Schroeder for their comments on the manuscript. This work was supported by NSF doctoral dissertation improvement grant \# BSR-8701000 to R. Barbehenn and NSF grant \# BSR-8421268 to M.M. Martin.

\section{References}

Ayres, M. P. \& S. F. MacLean Jr., 1987. Molt as a component of insect development: Galerucella sagitiariae (Chrysomelidae) and Epirrita autumnata (Geometridae). Oikos 48: 273-279.

Barbehenn, R. V., 1989. The nutritional ecology and mechanisms of digestion of $\mathrm{C}_{3}$ and $\mathrm{C}_{4}$ grass-feeding Lepidoptera. PhD Thesis. University of California, Berkeley.
Briese, D. T., 1986. Insect resistance to baculoviruses. In Granados, R. R. and B. A. Federici (eds), The Biology of Baculoviruses. CRC Press, Boca Raton, Florida: 237-263.

Chapman, R.F., 1982. The insects: structure and function. Harvard University Press, Cambridge, Mass.

Kogan, M., 1986. Bioassays for measuring quality of insect food. In Miller, J. R. and T. A. Miller (eds), Insect-Plant Interactions. Springer-Verlag, New York: 155-189.

Montgomery, M. E., 1983. Biomass and nitrogen budgets during larval development of Lymantria dispar and Choristonewra fumiferana: allometric relationships. In Talerico, R. and M. Montgomery (eds), Proceedings Forest Defoliator-Host Interactions. USDA Forest Service N.E Station. Gen. Tech. Rept. NE-85: 133-140.

Parra, J. R. P. \& M. Kogan, 1981. Comparative analysis of methods for measurements of food intake and utilization using the soybean looper, Pseudophsia includens and artificial media. Entomol. exp. appl. 30: 45-57.

Schroeder, L. A., 1984. Comparison of gravinetry and planimetry in determining dry malter budgets for three species of phytophagous lepidopteran larvae. Entomol. exp. appl. 35: 255-261.

Stamp, N. E., 1990. Growth versus molung tume of caterpillars as a function of temperature, nutrient concentration and the phenolic rutin. Oecologia 82: 107-113.

Waldbauer, G. P., 1968. The consumption and utilization of food by insects. Adv. Insect Physiol. 5: 229-289.

Wightman, J. A., 1981. Why insect energy budgets do not balance. Oecologia: 166-169.

Wilkınson, L., 1987. SYSTAT: the system for statistıcs. Evanston, IL: SYSTAT, Inc. 